\title{
BACTERIOSCOPIA VAGINAL POR COLORAÇÃO DE GRAM: DO ENSINO MÉDICO À PRÁTICA CLÍNICO-LABORATORIAL NA ROTINA EM GINECOLOGIA
}

\author{
José Marcos Sanches
}

Universidade Federal de São Paulo - UNIFESP, Doutorado em Biologia Estrutural e Funcional, São Paulo, SP. E-mail: josemarcos.sanches@yahoo.com.br

\section{RESUMO}

Este estudo teve como objetivo rever a prática do diagnóstico imediato por coloração de Gram em esfregaços vaginais na prática ginecológica. A importância é relatada pela melhor caracterização dos microrganismos presentes no conteúdo vaginal, para melhor compreensão dos processos de saúde e doença da mulher, bem como a busca por melhores diagnósticos e tratamento. Para isso, foram descritos os processos acerca do cenário no ensino médico em ginecologia e as novas perspectivas para melhor atender a população, de forma dinâmica e humanizada. Contudo, mediante as constantes mudanças no âmbito da saúde, é de fundamental importância que o médico seja muito bem capacitado e atue a fim de promover a saúde e o bem-estar de seus pacientes, utilizando recursos apreendidos no decorrer de sua formação para melhor atender a população.

Palavras-chave: Ensino médico, Ginecologia, Bacterioscopia, Coloração de Gram.

\section{VAGINAL BACTERIOSCOPY BY GRAM STAINING: FROM THE MEDICAL EDUCATION TO THE CLINICAL- LABORATORY PRACTICES IN GYNECOLOGY ROUTINE}

\begin{abstract}
The aims of this study was to review the practical of the immediate vaginal diagnosis by Gram staining in the gynecological practice. The elucidation and characterization of the vaginal microorganisms is important for providing a better understanding of the women's health and diseases, as well as the search for adequate diagnosis and treatment. Here we described the processes about the approaches in gynecological medical education scenery and its new perspectives in a dynamic and humanized way. However, due the constant changes in the health field, it is fundamentally important that the physicians and the multidisciplinary team are well trained to promote welfare of the patients, using the leaned resources acquired from their formation to better attend the population.
\end{abstract}

Keywords: Medical education, Gynecology, Bacterioscopy, Gram staining.

\section{INTRODUÇÃO}

A ação de ensinar é um caracterizador distintivo do docente, que ao longo do tempo, contextualiza-se em diferentes formas. As concepções históricas e conceituais acerca do ensino remetem a um perfil que se estende sobre a questão ensinar, natureza e construção do conhecimento profissional. Tendo como base 0 fato de que o ensino teórico é um elemento fundamental para a formação discente, esta ferramenta atua como um guia para interpretações de um determinado estudo, análises e as lança sobre o cotidiano ${ }^{1}$.

O currículo do curso de medicina é dotado de disciplinas que possibilitam ao aluno ter conhecimento da morfofisiologia humana, patologia, saúde pública e entre outras que através do ensino teórico-prático colaboram sua formação. Um fator imprescindível para a formação do médico é a prática realizada em laboratórios e no internato, onde o acadêmico em medicina realiza atividades rotativas entre as 
seis grandes áreas de aprendizado no ensino médico ${ }^{2}$.

Mediante a intensa atividade dos acadêmicos e preceptores no internato rotatório alguns conceitos básicos podem ser perdidos ou substituídos ao longo do tempo diante de uma possível intervenção clínica mais prática para um determinado caso. Na clínica ginecológica, por exemplo, muitos casos são avaliados apenas nos aspectos clínico e do histórico apresentado pela paciente ${ }^{3}$. 0 exame laboratorial para diagnóstico microbiológico das infecções do trato genital feminino tem como finalidade confirmar a suspeita clínica sobre uma determinada condição fisiopatológica ${ }^{4}$, porém esta prática nem sempre é utilizada na rotina médica.

A importância da prática do teste microbiológico durante o exame clínico ginecológico pode ser um meio para melhores conclusões sobre os processos de saúde e doença da mulher, sendo esta uma atividade que, por meio do incentivo do corpo docente, vincula esta prática a uma perspectiva mais eficaz no processo de ensino-aprendizagem, colaborando ainda na precisão do diagnóstico clínico. Portanto, este trabalho teve como objetivo relacionar a importância do ensino médico em ginecologia com a prática da bacterioscopia vaginal por coloração de Gram na rotina em ginecologia.

\section{MÉTODOS}

O estudo foi realizado por meio de revisão da literatura para verificar o processo de ensino teórico-prático em ginecologia e a viabilidade desta prática na rotina de ginecologia, do ensino à prática ambulatorial. A busca foi realizada a partir de artigos científicos publicados e disponíveis em texto completo, em língua portuguesa ou inglesa, indexados nas bases de dados: Medline, Web of Science, SciELO e Google Acadêmico. Não houve distinção para o tipo de estudo realizado, podendo assim englobar artigos mais atuais da literatura na de revisão, ensaios clínicos randomizados ou não, coortes e estudos de cortes transversais, sendo priorizadas as publicações mais atuais. Os descritores utilizados na busca foram: ensino médico, ginecologia, bacterioscopia, coloração de Gram.

As lâminas apresentadas neste estudo para a caracterização dos achados citológicos e microbiológicos foram cedidas pelo Ambulatório de Infecções Genitais Femininas do Hospital da
Mulher Prof. Dr. José Aristodemo Pinotti - Centro de Atenção Integral à Saúde da Mulher (CAISM), da Universidade Estadual de Campinas (UNICAMP). As amostras para as lâminas foram coletadas em um estudo anterior sobre infecções e disbioses vaginais, seguindo as normas e exigências do Comitê de Ética e Pesquisa (CAAE no 60648016.8.0000.5404), conforme a metodologia abaixo descrita.

O conteúdo foi coletado na parede vaginal com cotonete estéril e realizado um esfregaço amplo na lâmina. Os esfregaços foram deixados para secar por 15 minutos em temperatura ambiente, seguindo as seguintes etapas de adição dos corantes e lavagens:

- Violenta de cristal por um minuto, lavando com água após o tempo de fixação até retirar todo excesso de corante sobre o esfregaço;

- Lugol por um minuto, lavando com água após o tempo de fixação até retirar todo excesso de corante sobre o esfregaço;

- Álcool $90^{\circ}$ por $10 \mathrm{seg}$, lavando com água e;

- Safranina por $1 \mathrm{~min}$, lavando com água até retirar todo excesso de corante sobre 0 esfregaço, secando ao final com papel filtro.

As lâminas coradas pela técnica de coloração de GRAM foram interpretadas em microscópio óptico, no aumento de 1000x em óleo de imersão.

\section{RESULTADOS}

Ensino de ginecologia

A Ginecologia e Obstetrícia é considerada pelas Diretrizes Nacionais de Ensino como uma das grandes áreas de aprendizado ensino médico, sendo parte do currículo do curso de medicina durante o internato rotatório ${ }^{5,6}$.

Décadas atrás $\mathrm{o}$ aprendizado de Ginecologia e Obstetrícia era baseado no aprendizado de poucos e grandes mestres, que dominavam o conhecimento de forma abrangente. $O$ contato do aluno com o professor era intenso e geralmente ocorria à beira dos leitos ${ }^{7}$. Hoje, os acadêmicos de medicina percorrem durante sua formação por diferentes ambientes para exercer o treinamento das habilidades médicas, passando por ambulatórios, enfermarias, unidades básicas de saúde, clínicas e 
hospitais. Devido à superespecialização dos professores dentre as diversas especialidades e subespecialidades, os alunos são expostos a condutas e exemplos de docentes ou preceptores diversos, por vezes carentes de uma visão mais abrangente do cuidado à mulher e deslocados da realidade na qual a paciente está inserida ${ }^{7,8}$.

Com a finalidade de formatar as habilidades e competências na especialidade de Ginecologia e Obstetrícia tem sido realizada por sucessivas Comissões de Ensino e Avaliação da Federação Brasileira das Associações de Ginecologia e Obstetrícia (FEBRASGO), desde o ano de 2001, aproximadamente, por meio da formação do Conteúdo Programático da Residência Médica encaminhado pela FEBRASGO para a Comissão Nacional de Residência Médica. A determinação dos Programas de Residência Médica em Ginecologia e Obstetrícia deve possibilitar a capacitação do médico residente em Obstetrícia e Ginecologia a promover a saúde, prevenir, diagnosticar e tratar as afecções relacionadas à mulher em seus diversos níveis de complexidade, nas diferentes fases da vida, bem como desenvolver habilidades, raciocínio clínico, possibilitando uma visão mais crítica sobre as diversas áreas de atuação do médico ginecologista e obstetra9.

Mediante o intuito à formação de um médico mais generalista com visão mais ampla sobre os processos de saúde e doença do indivíduo e da população, o ensino médico tornase cada vez mais semelhante entre os planos de ensino nas instituições médicas ${ }^{5,6}$. O ensino de ginecologia permite ao acadêmico de medicina ter o aprendizado que compreende desde a morfologia e metabolismo genital feminino como os processos patológicos do trato genital superior e inferior ${ }^{9}$. A compreensão teórica reproduzida na prática ambulatorial, cirúrgica e clínica colabora para o melhor entendimento da fisiologia feminina e fundamentação do diagnóstico, prognostico e tratamento.

O conhecimento acerca das infecções e disbioses vaginais, integra o currículo nos anos iniciais da formação médica e mais especificamente nos internato onde $o$ aluno poderá integrar os conhecimentos teóricos à prática em ambulatórios de ginecologia, 5 . Mediante a proposta curricular de cada instituição, baseada nas diretrizes nacionais, torna-se cada vez mais importante que a prática em ginecologia possa integrar os conhecimentos clínico-laboratoriais aos discentes, fazendo com que aguce ainda mais o perfil investigativo dos alunos e assim poder promover a melhor resolução de casos dentre os diversos ambulatórios em ginecologia, especialmente em infecções genitais femininas o qual a prática laboratorial para o diagnóstico é bastante simples e acessível.

A formação médica fundamentada no ensino prático concomitante com uma base sólida teórica é a essência para a inserção de um médico capacitado para atender a população. $\mathrm{Na}$ prática ginecológica e obstétrica é fundamental que o médico esteja preparado e constantemente atualizado para atender da melhor maneira suas pacientes por meio da clínica médica bem estruturada para se aplicar à prática, oferecendo assim um serviço eficaz e humanizado.

\section{Diagnóstico microbiológico em ginecologia}

O microambiente vaginal pode influenciar direta ou indiretamente a mucosa vaginal, favorecendo ou dificultando a aquisição de novas infecções como Candidiases, vírus da imunodeficiência humana (HIV), Tricomoníase, entre outras. A instabilidade do ecossistema vaginal é um fator bastante conhecido pela clínica ginecológica e sua variação pode ser decorrente de diversos fatores, sejam eles fisiológicos ou externos. A microbiota vaginal é formada por diversos microrganismos, basicamente composta por espécies de lactobacilos (Figura 1), que promovem um equilíbrio do microambiente local, sendo este mantido por complexas interações entre a microbiota normal, os produtos metabólicos microbianos, o estado hormonal e a resposta imune do hospedeiro ${ }^{10}$. 


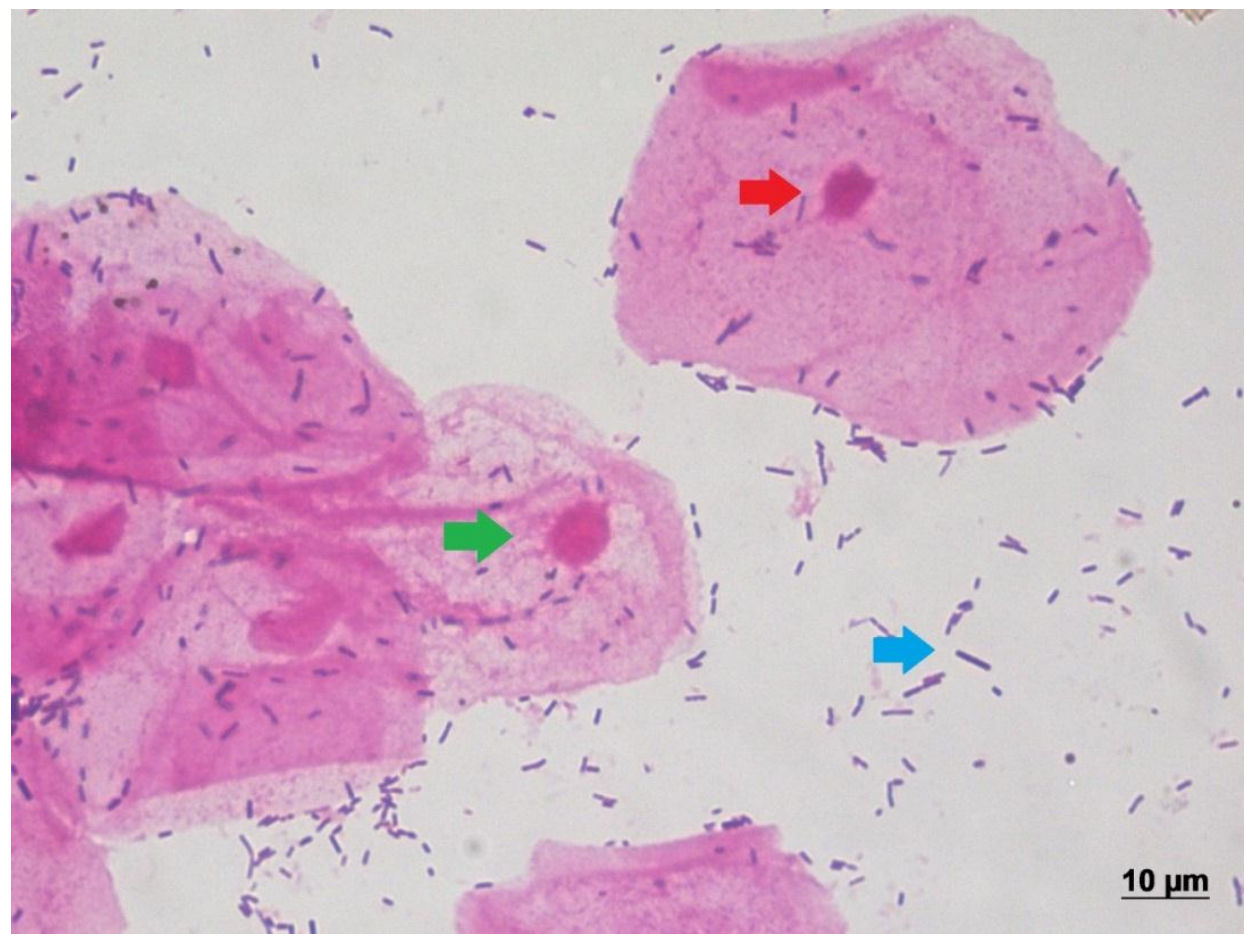

Figura 1. Esfregaço vaginal por coloração de Gram sem infecções ou disbioses vaginais. Presença de células intermediárias e superficiais íntegras do epitélio vaginal (setas verde e vermelha) e predominância de lactobacilos (seta azul). Ausência de lise intensa celular, processo inflamatório e agentes patológicos. Microscopia óptica com aumento de 1000x. Fonte: Ambulatório de Infecções Genitais Femininas - CAISMUNICAMP.

Durante a anamnese, de modo geral, o médico ginecologista utiliza-se do histórico relatado pela paciente e do diagnóstico clínico para fundamentar a clínica e o prognóstico ${ }^{11}$. Para uma paciente que chega ao ambulatório médico com queixas de corrimento vaginal, por exemplo, em muitos casos o médico responsável apenas remete às características do corrimento e do aspecto morfológico da paciente ao diagnóstico clínico, sem a devida comprovação do tipo de microrganismo causador do corrimento, apenas utilizando a microscopia e cultura em casos recorrentes para a confirmação do agente causador.

O diagnóstico microbiológico na prática de ginecologia está relacionado à detecção do agente patogênico para conclusão sobre determinada clínica de uma paciente, tomando como base a etiologia, clínica e prognóstico a fim de um tratamento mais eficaz ${ }^{12}$. Entre as possíveis e acessíveis formas de analisar dentro de clínicas e ambulatórios, a microscopia básica pode colaborar para a comprovação de uma patologia ginecológica. Uma simples coleta para coloração de Gram, por exemplo, é capaz de comprovar a etiologia para um descontrole fisiológico que acarreta em um corrimento vaginal.

A morfologia das bactérias pode ser observada por meio de coloração de Gram que divide as bactérias em dois grupos: Grampositivas e Gram-negativas. A reação das bactérias à técnica de Gram expressa diferentes características, de modo especial no que diz respeito a composição química, estrutura, permeabilidade da parede celular, fisiologia, metabolismo e patogenicidade ${ }^{13,14}$. Contudo, a coloração de Gram é aplicável na prática ginecológica para compreensão dos processos fisiológicos cervicovaginais e as interações dos microrganismos presentes.

Na prática clínica, o diagnóstico da VB é mundialmente feito por meio do método de Amsel et al. ${ }^{15}$, o qual preconiza que para o diagnóstico de VB é necessária a presença de pelo menos três dos seguintes critérios: presença de um corrimento vaginal fino e homogêneo; $\mathrm{pH}$ vaginal $\geq 4,5$; teste de wiff positivo (liberação de um odor de "peixe" característico ao se adicionar gotas de $\mathrm{KOH} 10 \%$ a uma fração do conteúdo vaginal) e a identificação das chamadas "clue cells" ou células indicadoras no exame microscópico a fresco do conteúdo vaginal, a qual 
pode ser definida como células epiteliais recobertas por bactérias. Ainda, a VB pode ser caracterizada por meio de pontuações pelos critérios de Nugent $^{16}$. A partir da coloração de Gram é possível diagnosticar a presença de microrganismos responsáveis pela VB, bem como diferenciar uma vaginose bacteriano do tipo 1 e do tipo 2 (Mobiluncus) (Figura 2).

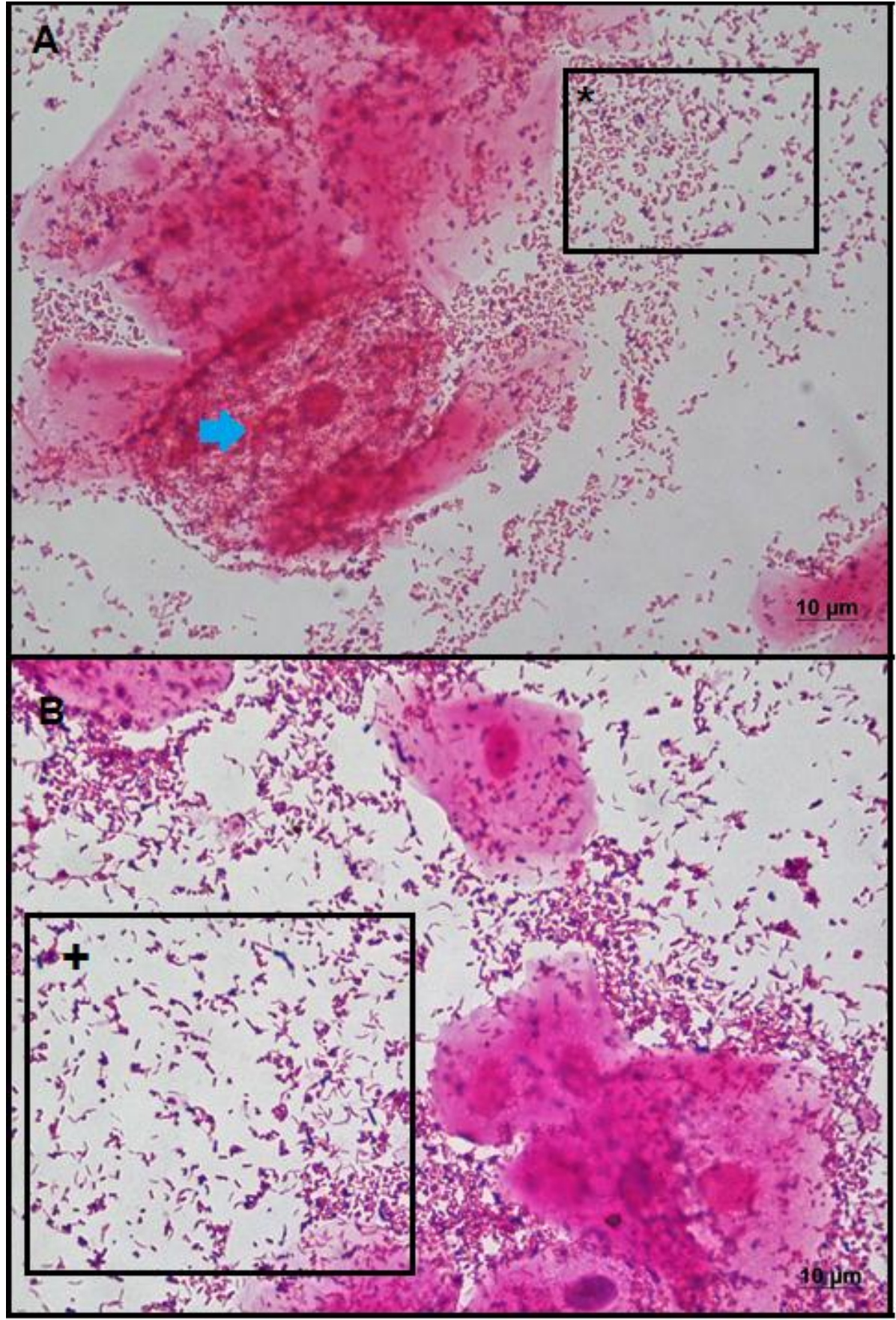

Figura 2. Esfregaços vaginais por coloração de Gram com diagnósticos de vaginose bactéria no tipo I e tipo II. Figura 2-A mostra os achados microbiológicos para a caracterização de vaginose bacteriana do tipo I se dão pela predominância de cocobacilos gram-positivos e gram-negativos (* no campo menor destacado), presença de clue-cells (seta azul), ausência de processo inflamatório e poucos ou nenhum lactobacilo. Figura 2-B mostra a vaginose bacteriana do tipo II no esfregaço vaginal com presença de Mobiluncus (+ no campo menor destacado) que são facilmente diferenciados pela sua morfologia de bacilo curvo gramnegativo, juntamente com cocobacilos gram-positivos e negativos. Microscopia óptica com aumento de 1000x. Fonte: Ambulatório de Infecções Genitais Femininas - CAISM-UNICAMP. 
A coloração de Gram é uma ferramenta fundamental para o diagnóstico microbiológico, de fácil confecção e interpretação, podendo ser executado por médicos, acadêmicos de medicina e outros profissionais da saúde ${ }^{17}$. Dentre outras infecções e descontroles da microbiota vaginal normal, a candidíase vaginal e vaginose citolítica (Figura 3), também podem ser facilmente confundidas uma vez que o médico baseia-se apenas na clínica e não verifica o aspecto microbiológico. A verificação do tipo de flora que compõe o trato vaginal, a presença de processo inflamatório e os agentes patológicos, por meio da confecção de lâminas coradas pela técnica de Gram, podem instituir um prognóstico eficaz ${ }^{18}$.
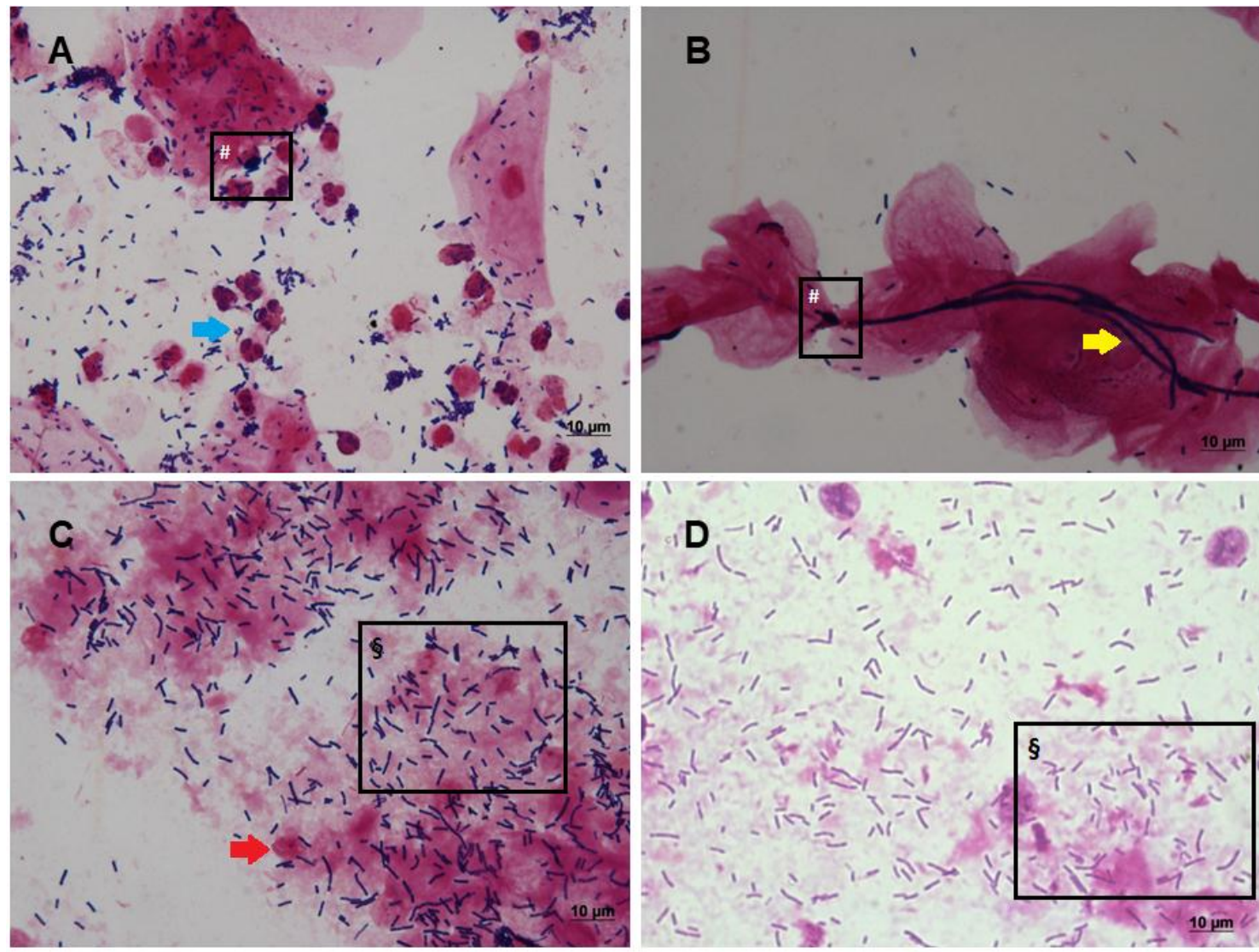

Figura 3. Esfregaços vaginais de candidíase vaginal e vaginose citolítica. Nas figuras 3-A e 3-B (\# no campo menor destacado) é possível verificar a presença de blastosporos de Candida sp. e a presença de polimorfonucleares (seta azul em 3-A) e hifas de Candida sp. (seta amarela em 3B). Na figura 3-C os achados que caracterizam a vaginose citolítica pela coloração de Gram se dão pela quantidade aumentada de lactobacilos (§ no campo menor destacado) e, em 3-D (§no campo menor destacado) presença de núcleos nus (seta vermelha) e lise intensa do epitélio vaginal. Microscopia óptica com aumento de 1000x. Fonte: Ambulatório de Infecções Genitais Femininas - CAISM-UNICAMP.

\section{DISCUSSÃO}

Diante do propósito curricular implantado no cenário da educação médica, as necessidades em atender ao sistema básico de saúde e a formação do profissional na área da medicina, é fundamental que a prática docente seja feita de forma estruturada e dinâmica, podendo corresponder de forma adequada à formação discente e às necessidades para as áreas da saúde. 0 aperfeiçoamento constantemente, não apenas para o exercício prático para o ato médico, mas também em sua didática e metodologia de aula deve ser buscado. Por meio da dinamização e efetividade em sua metodologia teórico-prática que o professor poderá realizar um trabalho em que os resultados serão claramente positivos de maneira ampla. Seja um professor de matérias básicas ou específicas da medicina ou preceptores, todos devem repensar sua forma de atuação docente, cujo benefício final será um bom profissional para a sociedade.

Grande parte dos atendimentos ginecológicos está relacionada às doenças e 
modificações morfofisiológicas do trato genital inferior feminino ${ }^{19}$. As possíveis interações fisiológicas ou ambientais se relacionam no processo de saúde e doença da mulher, tendo como um fator de defesa contra agentes patogênicos a mucosa vaginal, células de defesa, microrganismos presentes e outros, bem como as modificações deste ambiente podem acarretam na instalação e desenvolvimento de infecções ${ }^{10,20,21}$.

A inserção da prática microbiológica em ginecologia no ensino médico traz como perspectiva um adendo para a formação do profissional médico, pois pode colaborar para o melhor entendimento sobre os processos de saúde e doença da mulher. Em muitos casos, com a intensa atividade dos médicos preceptores nos ambulatórios algumas atividades básicas, como a confecção de lâminas para microscopia e análise de microrganismos é simplesmente substituída apenas pelo diagnóstico clínico. Com o intuito a melhores diagnósticos e tratamentos, a aplicação da técnica de Gram nos ambulatórios de genecologia pode acarretar diagnósticos mais fundamentados e precisos, como podemos verificar que, a partir da análise microbiológica por coloração de Gram (Figura 1) é possível distinguir infecções e disbioses vaginais que podem ser confundidas apenas pela clínica e queixas referidas pelas pacientes.

A prática ginecológica no internato dos cursos de medicina é dada em um determinado período onde os acadêmicos passam por clínicas, hospitais, unidades básicas de saúde, podendo exercer a prática médica apreendida no decorrer do curso $^{22,23}$. A ideia de implantar o diagnóstico microbiológico dentro do ensino médico, em ambulatórios de infecções ginecológicas, acarreta possibilidades de acrescentar conceitos básicos obtidos no início da graduação para a vida profissional. A simplicidade da técnica de Gram, por exemplo, pode atuar como uma ferramenta complementar para o diagnóstico clínico laboratorial, podendo ser executada e aferida logo após a coleta da secreção vaginal, pelos acadêmicos.

A institucionalização do preparo de lâminas para análise microbiológica, na prática ginecológica, pode ser incentivada pelos preceptores a fim de promover a aplicação desta técnica no cotidiano da clínica médica. Quando o aluno é capaz de visualizar o tipo de flora ao microscópio, bem como a patologia conferida na clínica, o diagnóstico torna-se mais preciso, viabilizando o tratamento adequando para a paciente. Contudo, o diagnóstico microbiológico por coloração de Gram remete a uma perspectiva simples de execução e de fundamental importância para a ginecologia.

\section{Conclusão}

Mediante novas perspectivas e necessidades da população para um sistema de saúde mais dinâmico e humanizado, o curso de medicina vem se adequando para melhor atender a população. A visão para a formação médica mais generalista, inserindo o aluno em práticas médicas que, muitas vezes precoce, pode acarretar perdas de fundamentos teóricos que infelizmente são perdidos ao longo dos anos de sua formação. É de fundamental importância que o médico em formação seja munido de bases teórico-práticas bem consolidadas para corresponder às necessidades da população. A prática ginecológica deve ser mantida por preceitos que promovam a saúde, prevenção e cuidados à mulher. A importância da prática microbiológica na clínica ginecológica, por coloração de Gram em esfregaços vaginais, para melhores diagnósticos de infecções genitais possibilita ao acadêmico uma melhor compreensão sobre os processos de saúde e doença acerca das patologias cervicovaginais, devendo ser incentivada esta prática pelos preceptores, pois a partir deste diagnóstico imediato o tratamento é mais direcionado, possibilitando um atendimento mais cuidadoso $\mathrm{e}$ eficaz.

\section{CONFLITO DE INTERESSE}

Os autores declaram não haver qualquer potencial conflito de interesse que possa interferir na imparcialidade deste trabalho científico.

\section{REFERÊNCIAS}

1. Roldão M C. Função docente: natureza e construção do conhecimento profissional. Rev Bras Educ. 2007;12(34):94-103. DOI: https://doi.org/10.1590/S141324782007000100008

2. Martins MA. Ensino Médico: editorial. Rev Assoc Médica. 2006;52(5):281-91. DOI: https://doi.org/10.1590/S0104$\underline{42302006000500002}$ 
3. Johnson NR, CHEN J. Medical student evaluation of teaching quality between obstetrics and gynecology residents and faculty as clinical preceptors in ambulatory gynecology. Am J Obstet Gynecol. 2006;195(5):1479-83. DOI: https://doi.org/10.1016/j.ajog.2006.05.038

4. Almeida PQ, Pereira MAP, Palomo FS, Okasaki C, Schimidt MA, Speck NMG, Robalta JCL. Accuracy of the cytopathology, bacterioscopy, and vaginal flora culture. Clin Exp Obstet Gynecol. 2013;40(2):243-5.

5. Brasil. Conselho Nacional de Educação, Câmara de Educação Superior. Diretrizes Curriculares Nacionais do Curso de Graduação em Medicina. Resolução CNE/CES №. 4, Brasília, 7 de novembro de 2001. p.1-6,

6. Souza PA, Zeferino AMB, Ros MA. Currículo integrado: entre o discurso e a prática. Rev Bras Educ Med. 2011;35(1):20-5. DOI: https://doi.org/10.1590/S0100-

\section{4}

7. Ferreira LC, Brito TM, Carvalho IGM, Ferreira RC. A percepção de acadêmicos sobre a relação médico paciente discutida em 8-8- oficinas problematizadas do caso do eixo teórico-prático integrado (CETPI). Rev Bras Educ Méd. 2015;39(1):119-22. DOI: https://doi.org/10.1590/1981$\underline{52712015 v 39 n 1 \mathrm{e} 01862013}$

8. Neman F, Ferreira KL, Castilho FS. Docência médica: trabalhando a informalidade. Sci Health. 2015;6(1):22-9

9. Amaral E, Azevedo GD, Abbade J. O ensino e o aprendizado de ginecologia e obstetrícia na graduação: desafios e tendências. Rev Bras Ginecol Obstet. 2007;29(11):551-4. DOI: https://doi.org/10.1590/S0100-

72032007001100001

10. Giraldo PC, Amaral RLGd, Gonçalves AK, Vicentini R, Martins $\mathrm{CH}$, Giraldo $\mathrm{H}$ et al. Influência da freqüência de coitos vaginais e da prática de duchas higiênicas sobre $o$ equilíbrio da microbiota vaginal. Rev Bras Ginecol Obstet. 2005:257:62.

DOI:

https://doi.org/10.1590/S0100-

$\underline{72032005000500005}$
11. Erekson EA, Iglesia CB. Improving patient outcomes in gynecology: the role of large data registries and big data analytics. J Minim Invasive Gynecol. 2015;22(7):1124-9.

DOI:

https://doi.org/10.1016/i.jmig.2015.07.003

12. Baruah FK, Sharma A, Das C, Hazarika NK, Hussain JH. Role of Gardnerella vaginalis as an etiological agent of bacterial vaginosis. Iran J Microbiol. 2014;6(6):409-14.

13. Burnett GW, Schuster GS. Microbiologia oral e enfermidades infecciosas. Rev Panam. 1982:3170.

14. Nisengard RJ, Newman MG. Oral microbiology and immunology. 2.ed. Philadelphia: Sauders; 1994.

15. Amsel R, Totten PA, Spiegel CA, Chen KCS, Eschenbach DA, Holmes KK. Nonspecific vaginitis: diagnostic criteria and microbial epidemiologic associations. Am J Med.1983;74:14-22. DOI: https://doi.org/10.1016/0002-9343(83)91112-9

16. Nugent RP, Krohn MA, Hillier SL. Reliability of diagnosing bacterial vaginosis is improved by a standardized method of gram stain interpretation. J Clin Microbiol. 1991;29(2):297301.

17. Brotman RM, Ravel J, Cone RA, Zenilman JM. Rapid fluctuation of the vaginal microbiota measured by Gram stain analysis. Sex Transm Infect. 2010;86(4):297-302. DOI: https://doi.org/10.1136/sti.2009.040592

18. Rice-Spearman L. The gram stain: still a diagnostic tool? Clin Lab Sci. 1993;6:16.

19. Cunningham F G. Ginecologia de Williams. Porto Alegre: Mc Graw Hill, Artmed, 2011

20. Sobel JD, Karpas Z, Lorber A. Diagnosing vaginal infections through measurement of biogenic amines by ion mobility spectrometry. Eur J Obstet Gynecol Reprod Biol. 2012;163(1):81-4. DOI: https://doi.org/10.1016/i.ejogrb.2012.03.022

21. Wolrath H, Stahlbom B, Hallen A, Forsum U. Trimethylamine and trimethylamine oxide levels in normal women and women with bacterial 
vaginosis reflect a local metabolism in vaginal secretion as compared to urine. APMIS. 2005;113(7-8):513-6.

DOI:

https://doi.org/10.1111/j.1600-

0463.2005.apm 175.x

22. Norcini JJ, McKinley DW. Assessment methods in medical education. Teach Teacher Educ. 2007;23(3):239-50.

https://doi.org/10.1016/j.tate.2006.12.021

23. Amaral E, Zeferino A, Nadruz W, Antonio MA, Sarian L, Inhaia C, Leite RC, Mennin SP. Successful accomplishment of educational goals with clinical experience at public primary care facilities. Med Teach. 2007;29(6):600-5. DOI: https://doi.org/10.1080/01421590701506858

Recebido para publicação em 22/08/2016

Revisado em 24/04/2017

Aceito em 14/06/2018 